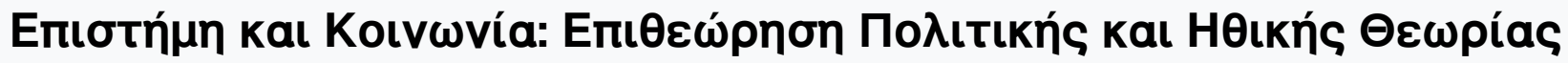

Tó 24 (2010)

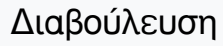

Teủxos 24 Avoıł̣n 2010

http://www.media.uoa.gr/sas

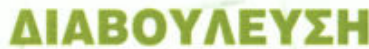

rıávvns namaðónouגos

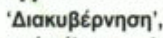

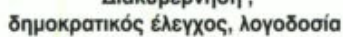

\section{Euáyveגoc Aıótלns}

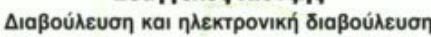

Апнйтрпs Гкои́бкоя

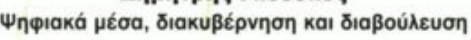

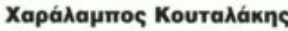

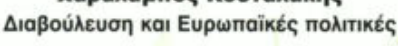

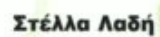

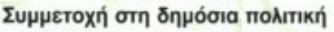

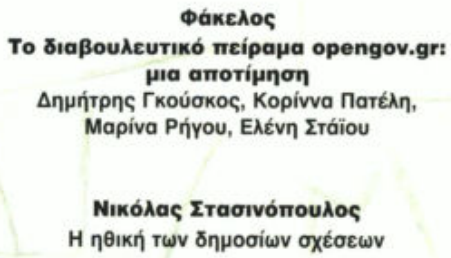

ФáкعAos

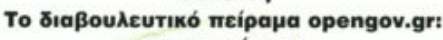

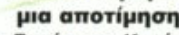

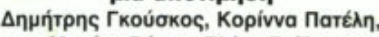

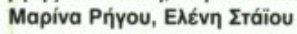

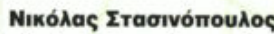

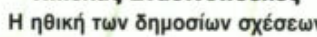

\section{इ三}

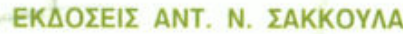

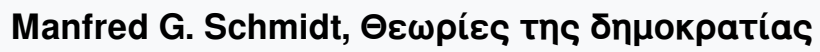

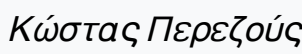

doi: $\underline{10.12681 / \text { sas. } 910}$

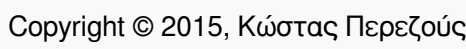

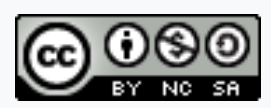

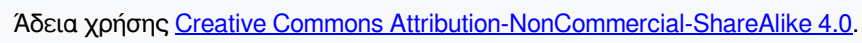

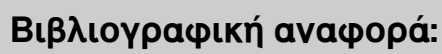

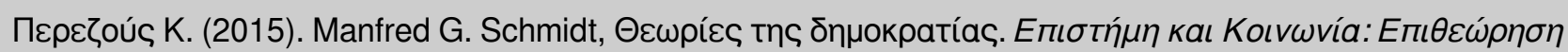

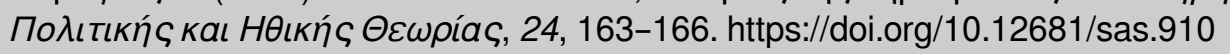




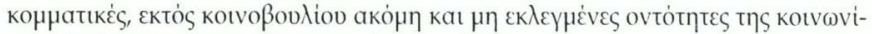

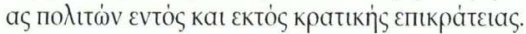

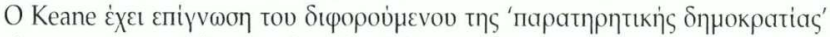

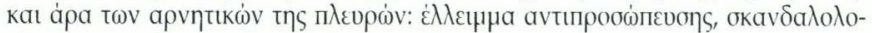

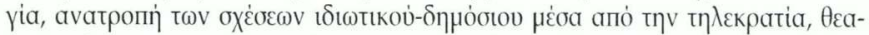

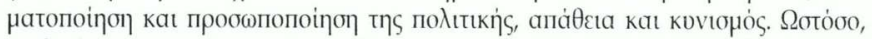

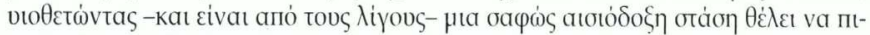

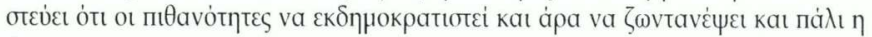

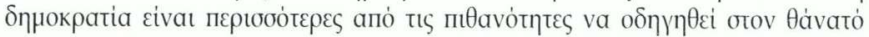
tins.

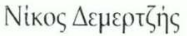

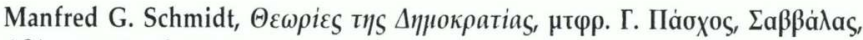

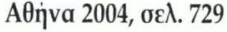

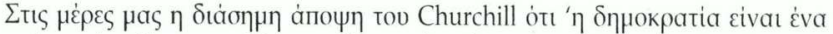

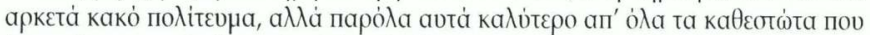

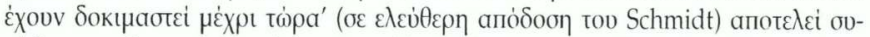

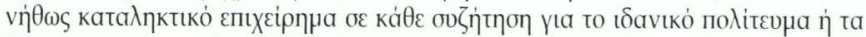

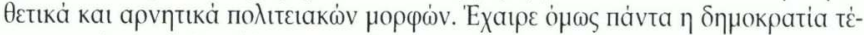

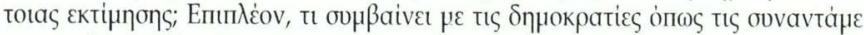

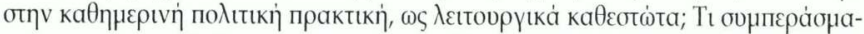

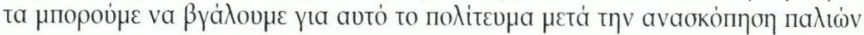

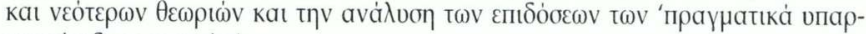

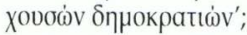

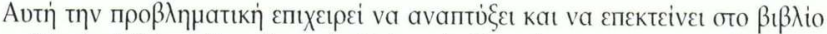

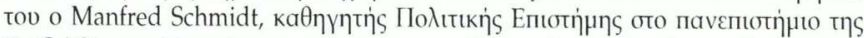

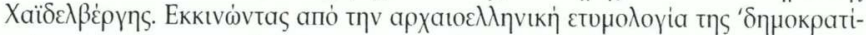

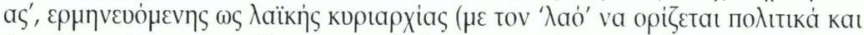

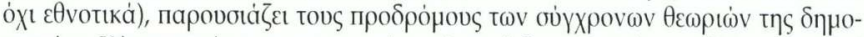

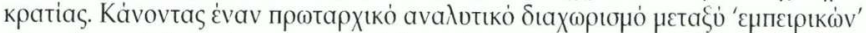

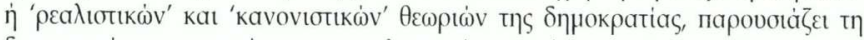

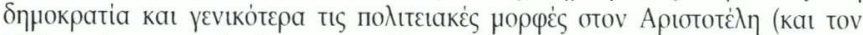

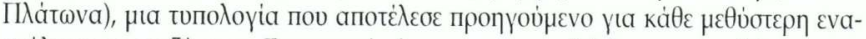

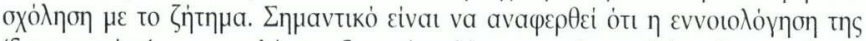

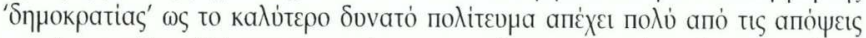

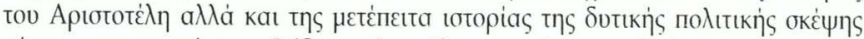

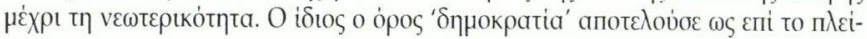




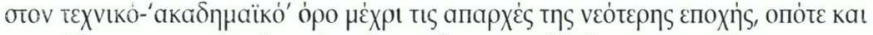

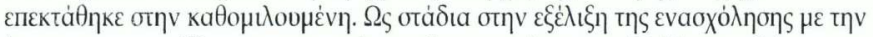

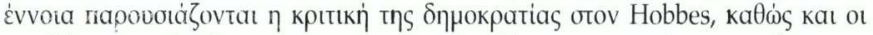

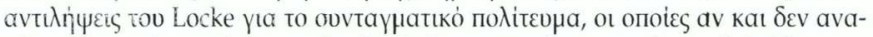

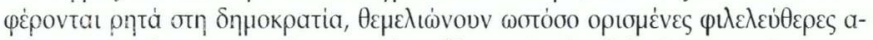

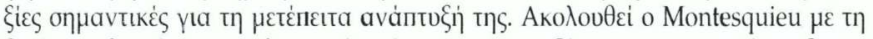

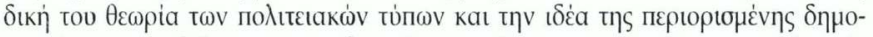

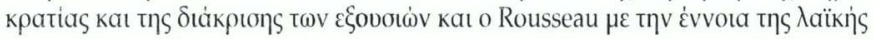

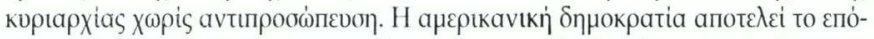

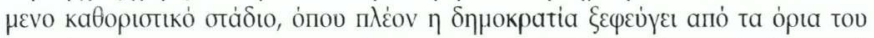

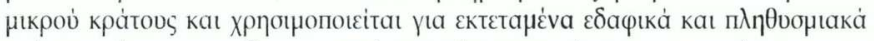

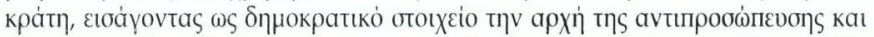

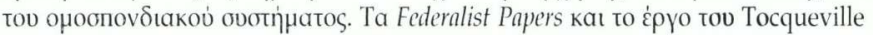

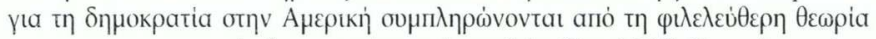

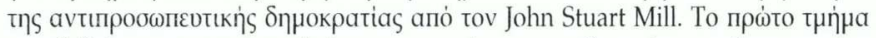
tov $\beta$ «

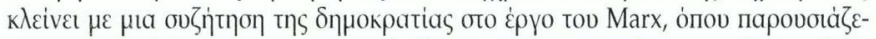

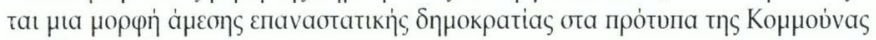
tov Пlaptotoú.

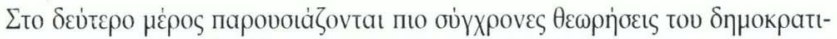

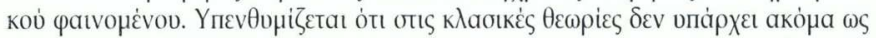

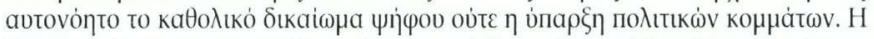

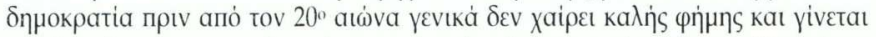

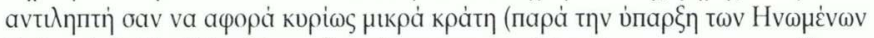

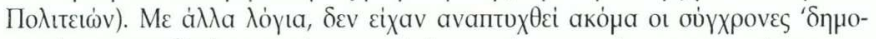

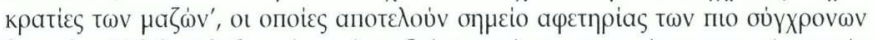

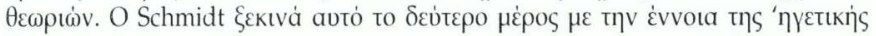

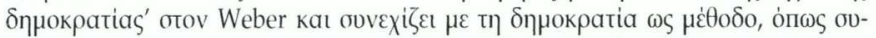

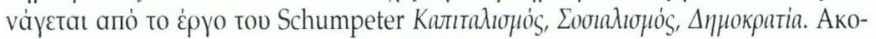

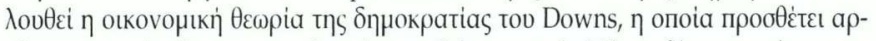

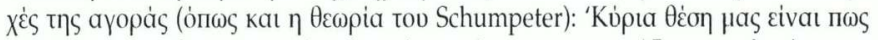

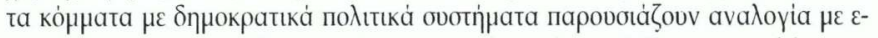

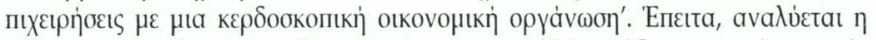

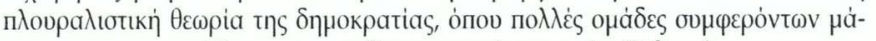

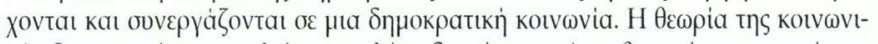

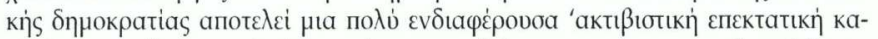

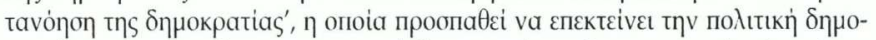

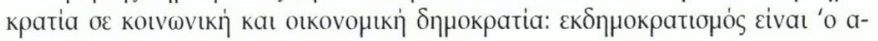




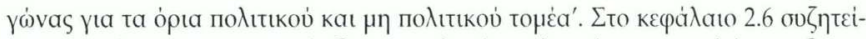

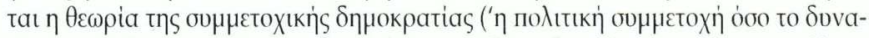

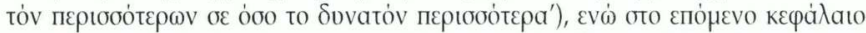

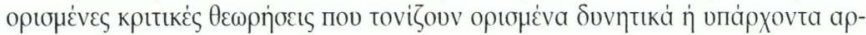

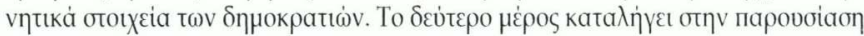

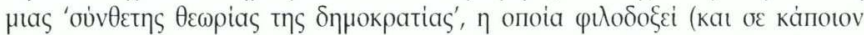

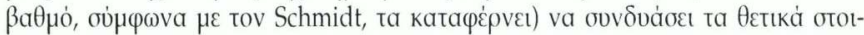

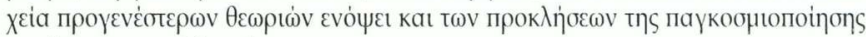

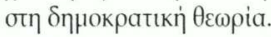

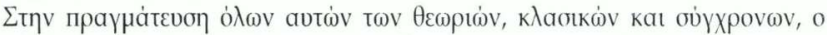

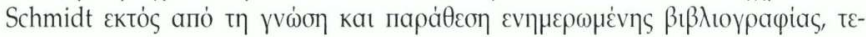

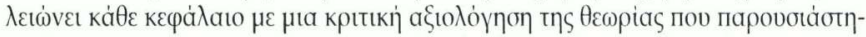

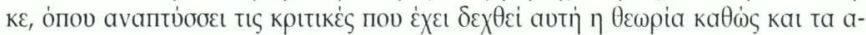

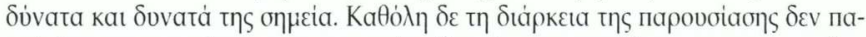

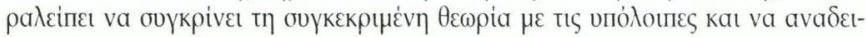

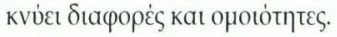

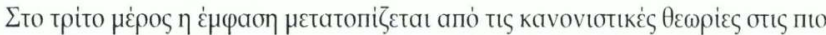

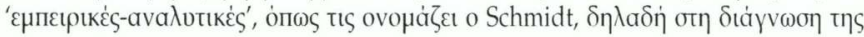

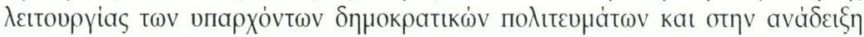

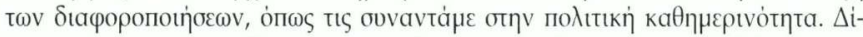

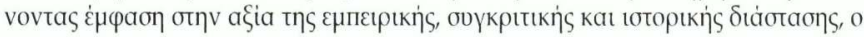

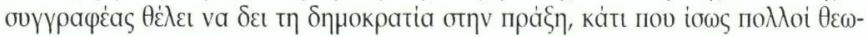

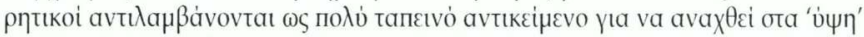

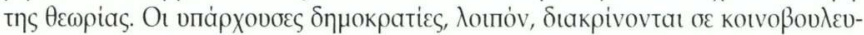

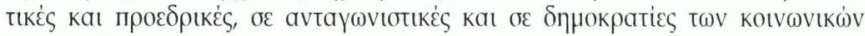

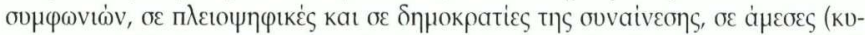

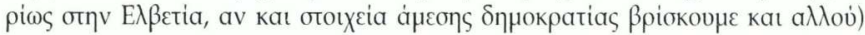

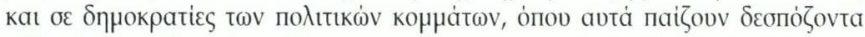

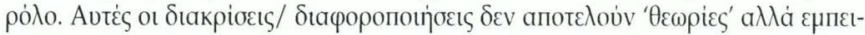

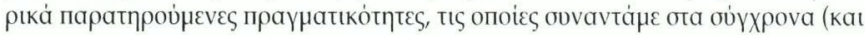

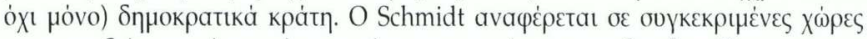

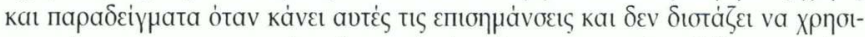

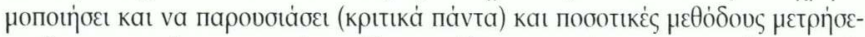

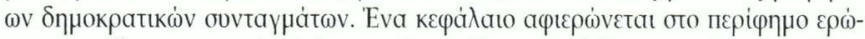

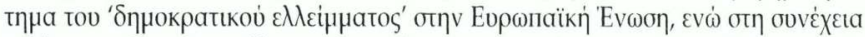

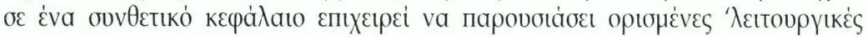

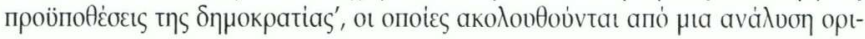




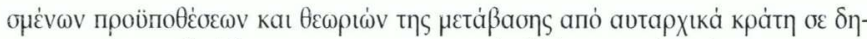

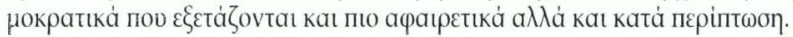

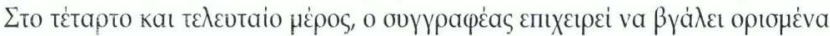

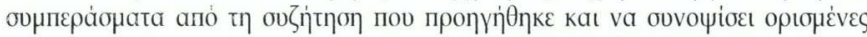

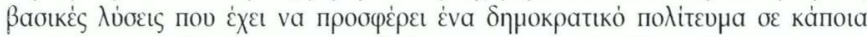

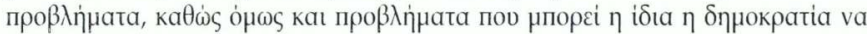

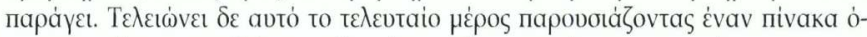

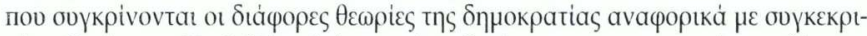

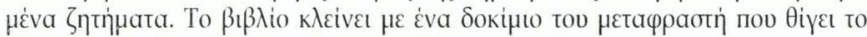

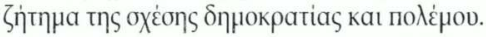

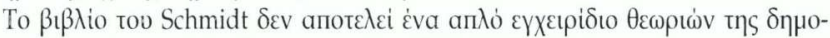

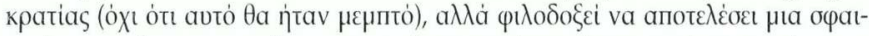

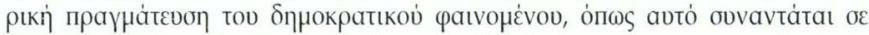

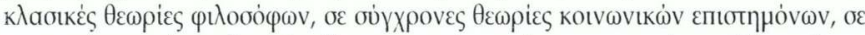

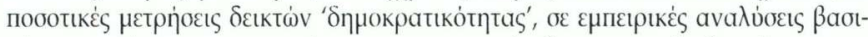

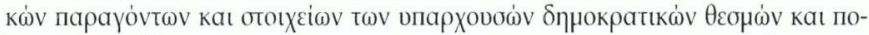

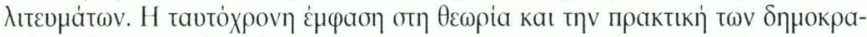
тเ

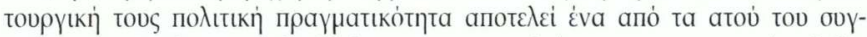

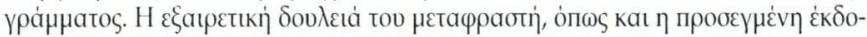

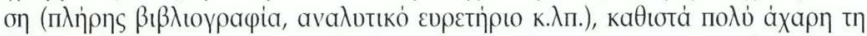

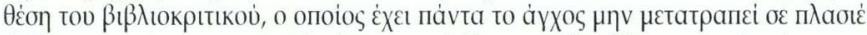

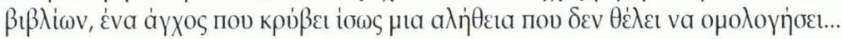

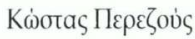

\section{Richard Sennett, The Culture of the New Capitalism, New Haven: Yale Univer- sity Press 2006, бहג. 214}

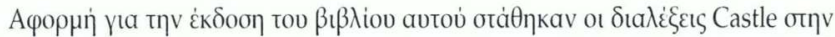

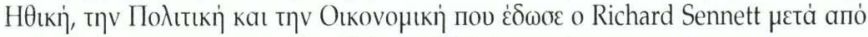

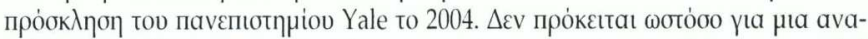

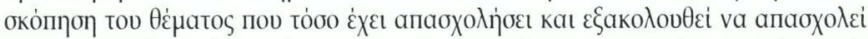

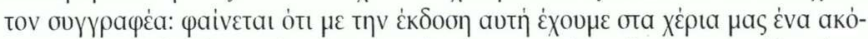

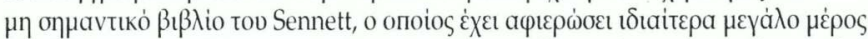

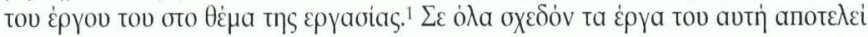

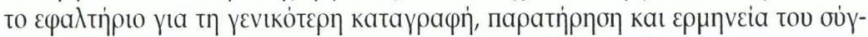

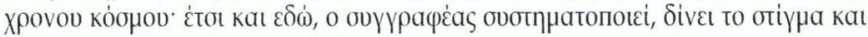

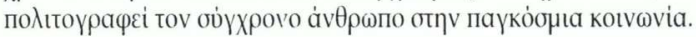

